\title{
A indisciplina na instituição escolar: o trabalho com assembleias de classe no desenvolvimento de crianças morais autônomas
}

Indiscipline in schools: working with class meetings

in developing morally autonomous children

Carmen Lúcia Dias*

Universidade do Oeste Paulista

Terezinha Ferreira da Silva Colombo**

Instituto de Ensino Superior de Garça

Resumo Os problemas de indisciplina e violência em suas diversas manifestações na sala de aula e na escola tanto pública como particular, têm se constituído num dos principais desafios para os educadores. No que tange à sala de aula, como mecanismo de superação propõem-se as assembleias de classe, objetivo do presente estudo, visando à construção de sujeitos morais autônomos. Partindo-se de situações vivenciadas no contexto escolar por crianças de 7- 8 anos, pertencentes a uma escola de ensino fundamental pública, procurouse evidenciar sua importância por meio da análise do pensamento e do desenvolvimento da moralidade deste grupo, abrangendo dilemas reais surgidos da convivência entre professor/aluno/aluno. A importância da utilização de recursos como as assembleias de sala de aula, fica demonstrada no presente estudo, com a possibilidade de construção da autonomia moral.

PALAVRAS-CHAVE: Indisciplina, Assembleias de classe, Ensino Fundamental.

Abstract The problems with discipline and violence in their several manifestations in classrooms in both public and private schools have been a major challenge for educators. Regarding the classroom environment, the purpose of this study was to propose class meetings as a coping mechanism, aiming to build morally autonomous subjects. From the description of situations experienced within the school context by children between seven and eight years old who study in a public elementary school, we tried to emphasize its importance through the analysis of thoughts and the moral development in this group, involving real dilemmas emerging from the familiarity between teacher-student and student-student. The importance of using resources such as class meetings is evidenced in this study which may result in the building of moral autonomy.

KEYWORDS: Indiscipline, Class meetings, Basic Education. 


\section{Introdução}

Os problemas de indisciplina e violência em suas diversas manifestações na sala de aula e na escola, tanto pública como particular, têm se constituído num dos principais desafios para os educadores. Tais problemas vêm afetando o contexto escolar em diversos aspectos como as relações interpessoais em sala de aula, constituindo-se em um cenário permeado por diversas questões a serem investigadas.

Optamos neste estudo por considerar os atos de indisciplina ${ }^{1}$ escolar como sendo parte da violência. Na literatura internacional são utilizados os nomes de microviolência ou violência miúda para caracterizar os casos mais leves de indisciplina como xingamentos, insultos, agressões verbais, brigas leves, ameaça à honra e ao pudor, falta de respeito com colegas e professores, falta de caráter, mentiras, comportamentos e gestos ofensivos, zombaria, recusa a trabalhar em grupo, desobediência gratuita, intimidação e empurrões; enquanto comportamentos como lesão corporal de natureza grave, roubos, extorsões, porte e uso de arma branca ou de fogo constituem a violência propriamente dita (PAPPA, 2003).

A (in)disciplina na escola é um assunto pesquisado por vários autores, dentre eles Aquino (2000); Vasconcellos (2000); Argüís (2002); La Taille, Silva e Justo (2006), Tognetta e Vinha (2008); Parrat-Dayan (2008), tendo em vista que as crianças e adolescentes mostram-se pouco acostumados a vivenciar e a respeitar os limites que visam assegurar a sobrevivência de si e a do grupo no qual estão inseridos (LA TAILLE; SILVA; JUSTO, 2006). A indisciplina é, em parte, produzida pelas relações interpessoais e poderá ser superada com a promoção de um trabalho amplo relacionado aos aspectos sociais. E, no que tange à sala de aula, propostas de superação se apresentam, dentre as quais as assembleias de classe, como proposta principal desta pesquisa.

As assembleias, de acordo com Puig (2000), destinam-se a um momento organizado para que os membros da escola possam dialogar com o objetivo de melhorar a convivência e o trabalho escolar. Nesse sentido, o espaço das assembleias de classe não se destina exclusivamente à resolução de conflitos, pois isso faria com que fosse um momento sempre de tensão e não prazeroso. Este é o momento também de se falar das coisas positivas, de felicitar as conquistas pessoais e do grupo e de se discutir temáticas para projetos futuros.

O espaço das assembleias de classe permite experiências conceituais concretas e práticas de democracia na escola, uma oportunidade para favorecer a construção da autonomia moral dos alunos, vivenciando um ambiente cooperativo, possibilitando ações voltadas para o diálogo, a reciprocidade, o respeito mútuo, contribuindo para a educação moral e para a cidadania.

Portanto, o objetivo do presente estudo é evidenciar a importância das assembleias de classe, visando a construção de sujeitos morais autônomos, através de relações de cooperação, reciprocidade e respeito mútuo, com a perspectiva de 
superação da indisciplina. Partindo-se de situações vivenciadas no contexto escolar por crianças de 7-8 anos, pertencentes a uma escola de Ensino Fundamental pública, procurou-se evidenciar tal importância por meio da análise do pensamento e do desenvolvimento da moralidade (DELVAL, 2002) desse grupo, abrangendo dilemas reais surgidos da convivência entre professor/aluno e aluno/aluno.

\section{O ambiente escolar e as relações interpessoais}

O trabalho em sala de aula não transcorre baseado apenas na cognição (VASCONCELLOS, 2000); se assim fosse, grandes problemas estariam resolvidos; ocorre que, na realidade, há uma grande carga afetiva envolvida, podendo passar por agressão, busca de afeto ou aceitação, e por fim, enfrentando situações de conflito - há que se fazer todo um trabalho educativo, preventivo, mas os problemas acontecem como o desrespeito às normas; o que se deve fazer é superá-los com coerência, conscientização e diálogo. O processo educativo e, mais especificamente, a construção do conhecimento são processos interativos e, portanto, sociais, nos quais os agentes que deles participam estabelecem relações entre si. Nessa interação, eles transmitem e assimilam conhecimentos, trocam ideias, expressam opiniões, compartilham experiências, manifestam suas formas de ver e conceber o mundo e veiculam valores que norteiam suas vidas.

Portanto, a interação humana tem uma função educativa, pois é convivendo com os seus semelhantes que o ser humano é educado e se educa.

No processo de construção do conhecimento, o valor pedagógico da interação humana é ainda mais evidente, pois é por intermédio da relação professor-aluno e da relação aluno-aluno que o conhecimento vai sendo construído coletivamente.

A escola (AQUINO, 1996), por sua vez, além de seu espaço de (re) produção científica e cultural, não deve se eximir de sua normatização atitudinal. Porém, o que se vê hoje é que muitas de suas funções ultrapassam o âmbito pedagógico (sendo a ela delegada a normatização da conduta alheia) e que implicam o (re)estabelecimento de algumas atribuições familiares.

A vida em sociedade (REGO, 1996) pressupõe a criação e o cumprimento de regras e preceitos capazes de nortear as relações, possibilitar o diálogo, a cooperação e a troca entre membros deste grupo social. A escola, por sua vez, também precisa de regras e normas orientadoras do seu funcionamento e da convivência entre os diferentes elementos que nela atuam. Normas que deixariam de ser vistas como prescrições castradoras, mas compreendidas como necessárias ao convívio social no qual se privilegia as relações de cooperação, de reciprocidade e respeito mútuo, caminho necessário para a autonomia.

Assim, por um lado, nos leva a reconhecer que a escola não pode se isentar de sua tarefa educativa no que se refere à disciplina. 
Se uma de suas metas é a de que os alunos aprendam as posturas consideradas corretas em nossa cultura (tais como apresentar atitudes de solidariedade, cooperação e respeito aos seus colegas e professores), a prática escolar cotidiana deve dar condições para que os alunos não somente conheçam essas expectativas, mas também construam e interiorizem esses valores.

Para tanto, a escola e os educadores precisam adequar suas exigências às possibilidades dos alunos (suas possibilidades cognitivas e motoras, a sua capacidade de concentração, compreensão de determinadas matérias, etc.). Assim, os alunos, mais do que obedecerem às regras estabelecidas devido ao receio de punições e ameaças (nota baixa, advertência para os pais assinarem, suspensão das aulas, etc.), precisam ter a oportunidade de conhecer (e discutir) as intenções que as originaram, assim como as consequências caso sejam infringidas (REGO, 1996).

Isso nos faz refletir sobre a educação moral:

[...] crianças precisam sim aderir a regras (que implicam valores e formas de conduta) e essas somente podem vir de seus educadores, pais ou professores. Os "limites" implicados por essas regras não devem ser apenas interpretados no seu sentido negativo: o que não pode ser feito ou ultrapassado. Devem também ser entendidos no seu sentido positivo: o limite situa, dá consciência de posição ocupada dentro de algum espaço social - a família, a escola, e a sociedade como um todo. (LA TAILLE, 1994 apud REGO, 1996, p. 86)

Vale ressaltar que, para Piaget (1994, p. 23), "toda moral consiste num sistema de regras e a essência de toda moralidade deve ser procurada no respeito que o indivíduo adquire por estas regras".

Referindo-se sobre estudos da moralidade humana, Montoya coloca que a grande descoberta da Psicologia Genética é ter invertido o tratamento clássico dado à moralidade humana.

Embora exista, nos estudos clássicos da moral, consenso sobre o fato de o respeito constituir o sentimento fundamental que possibilita a aquisição das noções morais, as formas de tratamento dessa relação é que podem ser diametralmente opostas. Assim, segundo Piaget (1998), enquanto Kant vê no respeito um resultado da lei e Durkheim um reflexo da sociedade, Bovet mostra, ao contrário, que o respeito pelas pessoas constitui um fato primário e que mesmo a lei dele deriva. Para Bovet (1912), duas condições são necessárias e suficientes para que se desenvolva a consciência da obrigação: em primeiro lugar, que um indivíduo dê ordens a outro e, em, segundo, que esse outro respeite aquele de quem emanam as ordens. Noutras palavras, é suficiente que a criança respeite seus pais ou professores 
A indisciplina na instituição escolar: o trabalho com assembleias de classe no desenvolvimento de crianças morais autônomas

para que as ordens prescritas por eles sejam aceitas por ela e por isso se tornem obrigatórias. Esse resultado, para Piaget, é essencial para a educação moral, posto que leva logo de início a situar as relações de indivíduo a indivíduo acima de qualquer ensinamento oral e teórico[...]. (MONTOYA, 2004, p. 176)

Ainda desse autor, deste novo modo de colocar a relação entre o respeito e a lei moral faz-se necessário diferenciar as modalidades que assumem o respeito na relação entre os indivíduos. Assim, Piaget em suas pesquisas distingue dois tipos de respeito: o respeito unilateral, implicando na desigualdade entre aquele que respeita e aquele que é respeitado (como o respeito do pequeno pelo grande, da criança pelo adulto) característico da relação social que Piaget chama de relação de coação. Por outro lado, o respeito mútuo, no qual indivíduos que estão em contato se consideram iguais e se respeitam reciprocamente: ao que Piaget chama de relação de cooperação, essencial para as relações entre crianças ou entre adolescentes num jogo regulamentado, numa organização de autogoverno ou numa discussão sincera e bem conduzida.

Esses dois tipos de respeito apresentados explicam a existência de duas morais: a resultante das relações de coação moral e do respeito unilateral, conduzindo ao sentimento do dever: heteronomia moral; a autonomia moral, resultante do respeito mútuo e das relações de (co)operação, caracterizando-se por um sentimento diferente, o sentimento do bem, mais interior à consciência, cujo ideal de reciprocidade tende a tornar-se inteiramente autônomo (MONTOYA, 2004; LA TAILLE, 1992).

É importante observar o que mostram as pesquisas psicogenéticas sobre a moral:

[...] a melhor forma das instituições educacionais contribuírem na formação de indivíduos autônomos é pela educação moral ativa, isto é, pelo favorecimento de experiências morais não apenas de coação - que são inevitáveis nas práticas morais autoritárias -, mas também, e sobretudo, de cooperação [...]. (MONTOYA, 2004, p. 177)

\section{As assembleias no âmbito escolar}

Ao se referir às escolas democráticas, Puig considera as assembleias como "o momento institucional da palavra e do diálogo. Momento em que o coletivo se reúne para refletir, tomar consciência de si mesmo e transformar o que seus membros consideram oportuno, de forma a melhorar os trabalhos e a convivência" (PUIG, 2000, p. 86). Estas se caracterizam: de classe, de nível ou segmento, de escola e de docentes 2 . Para o nosso estudo em questão, destacaremos as assembleias de classe.

As assembleias de classe (ARGÜÍS, 2002; TOGNETTA; VINHA, 2008) promovem discussões e reflexões acerca de dilemas e de outras situações apresentadas. As temáticas oriundas do contexto de sala de aula têm como 
objetivos regular e regulamentar a convivência e as relações interpessoais por meio do diálogo. O exercício do pensar em diversos âmbitos e possibilidades promove avanços morais determinados pela mediação do pesquisador em propor resoluções que provoquem conflitos cognitivos. Puig (1988) afirma que, à medida que os conflitos decorrentes das proposições oferecidas são resolvidos, o pensamento moral evolui em direção à autonomia e à cooperação no ambiente escolar.

Ainda, de acordo com Argüís (2002), as assembleias de classe determinam um momento em que há a instituição do diálogo organizado, objetivando promover através destas um elemento essencial em uma escola democrática: a educação em valores. Durante as assembleias, os protagonistas do processo educativo têm a palavra para resolverem situações emergentes desse espaço, incrementando a eficácia escolar.

A possibilidade de um clima de melhor convivência nas escolas perpassa, em alguma medida, por questões que possam ser consideradas e discutidas coletivamente.

As assembleias escolares são um espaço de educação moral, porque nelas introjetam-se valores como respeito, a colaboração, a solidariedade ou a justiça, e exercem-se capacidades psicomorais, como a empatia, o diálogo, a compreensão, o juízo ou a autorregulação [...]. (ARGÜÍS, 2002, p. 28)

Portanto, as assembleias são uma oportunidade para que as pessoas nela envolvidas se sintam pertencentes ao grupo e responsáveis por esse; promove o respeito mútuo, "[...] onde se praticam a autorregulação e a cooperação" (DE VRIES; ZAN, 1997 apud TOGNETTA; VINHA, 2008, p. 105). Assim sendo, elas se traduzem "como possibilidade de evolução moral dos sujeitos que delam participam. E é justamente esse o grande objetivo da escola: formar sujeitos autônomos" (TOGNETTA; VINHA, 2008, p. 60).

Para Piaget (1998), um mecanismo de fundamental importância para o exercício da autorregulação vincula-se à prática do self-government, um procedimento de educação social que tende, como todos os outros, a ensinar os indivíduos a sair do seu egocentrismo para colaborarem entre si e a se submeter a regras comuns, ou seja, no caso da escola, confia aos alunos a organização da disciplina escolar. Pelo self-government, o estudante desenvolve em classe uma solidariedade nova, o sentimento da igualdade e da justiça e a noção de sanção fundada na reciprocidade. Cabe ressaltar, ainda de acordo com Piaget, que a prática do self-government só atinge seu pleno rendimento a partir dos onze anos aproximadamente.

Com relação à organização das assembleias, a estas devem se destinar um tempo semanal, uma ou mais vezes por semana, de acordo com a demanda. Os alunos devem considerá-las como uma reunião habitual de sala de aula, que podem usá-la para alcançarem diversas finalidades. $\mathrm{O}$ espaço disposto em sala de aula deve ser de forma distinta da habitual, favorecendo o diálogo, sendo o 
A indisciplina na instituição escolar: o trabalho com assembleias de classe no desenvolvimento de crianças morais autônomas

círculo a maneira mais adequada para fortalecer, com esse simbolismo, a atitude de cooperação entre todos os membros. O tempo atribuído à assembleia deve ser utilizado para que sejam discutidos juntos os assuntos que os membros consideram importantes e merecedores da atenção dos colegas. O diálogo como fonte essencial da assembléia tem a função de organizar o trabalho e solucionar os conflitos de convívio que possam apresentar-se, contando também com o comprometimento pessoal nas ações que serão executadas. $\mathrm{O}$ modo de realização das assembleias de sala de aula dependerá da idade dos alunos que dela participam, respeitando as especificidades próprias de cada faixa etária (ARGÜÍS, 2002).

Ainda de acordo com o autor, as assembleias possuem algumas funções, sendo elas: a de informar, com o objetivo de utilizar este espaço para dar a conhecer tudo aquilo que considere relevante e que diga respeito à vida da coletividade; o papel de analisar o que ocorreu, o sentido do que foi vivido, as causas dos problemas ou as dificuldades que permeiam as tarefas escolares, conflitos de convivência que aparecem; decidir, organizar o que se quer fazer e, por fim, promover a autorregulação da turma, derivando daí os projetos de trabalho e as diretrizes de convivência que passarão a direcionar, depois daquele momento, o grupo-classe.

Portanto, sua implementação solicita a transformação das relações interpessoais, ao mesmo tempo em que interve na construção psicológica e moral de seus agentes, atuando na multidimensionalidade constituinte dos sujeitos que frequentam esse espaço (PUIG, 2000).

\section{O trabalho com crianças e o método clínico de Piaget}

Com o objetivo de demonstrar a importância das assembleias de classe, na perspectiva de superação da indisciplina, partiu-se de situações vivenciadas no contexto escolar por 37 crianças, entre 7-8 anos, pertencentes a uma escola de Ensino Fundamental pública. Procurou-se evidenciar tal importância por meio da análise do pensamento e do desenvolvimento da moralidade (DELVAL, 2002) desse grupo, abrangendo dilemas reais surgidos da convivência entre professor/ aluno e aluno/aluno. Os sujeitos foram identificados por letras para garantir o anonimato.

A pesquisa de abordagem qualitativa, com duração de dois semestres letivos, utilizou-se do método clínico piagetiano (DELVAL, 2002), indispensável para compreender as ações do sujeito, a promover intervenções e a interpretar seus significados. $\mathrm{Na}$ coleta de dados foram utilizados registros diários, com auxílio de gravador, caderno-diário e de um(a) secretário(a), geralmente um aluno com facilidade na escrita, o qual se manifestava ou era convidado para a função, anotando os assuntos principais e as decisões tomadas durante as assembleias (ARGÜÍS, 2002). A partir dos dados obtidos, advindos da convivência do grupoclasse, constitui-se um rico material disposto na forma de dilemas (PUIG, 1998). 
Tendo como proposta o ambiente cooperativo em sala de aula, os dilemas reais foram apresentados nas assembleias, oportunizando o exercício do pensar, do diálogo, do direito à fala, a busca de resoluções de conflitos e outras situações apresentadas, validando o respeito mútuo como princípio norteador das relações interpessoais.

Dentre os temas abordados, foram selecionados os dilemas: empréstimo de materiais aos colegas (pode ou não emprestar?); a construção coletiva de regras; regra do jogo de figurinhas: conflito devido ao não cumprimento da regra; meu amigo xingou minha mãe, e agora?; o que fazer quando o aluno não cumpre as regras da sala de aula?; ida ao banheiro: pedir ou não permissão à professora?; o não cumprimento de uma regra que passou despercebida - deve ou não haver punição?

Os dilemas descritos foram categorizados segundo critérios utilizados por Piaget (1994) e sistematizados por Delval (2002). Mediante o que foi apresentado, foram levadas em conta as respostas diferenciadas e o trabalho de análise dos dados obtidos pelo método clínico foi iniciado pela análise qualitativa, dando sentido às informações e descobrindo tendências e explicações gerais do material coletado.

Segundo Piaget, no método clínico, há diferentes tipos de respostas que devem ser conhecidas e levadas em conta: as respostas espontâneas; as respostas desencadeadas; as respostas sugeridas; as fabuladas e as respostas não-importistas (DELVAL, 2002). As respostas espontâneas possuem um valor imprescindível na entrevista, ou seja, no momento das assembleias, por meio de perguntas bem elaboradas, a criança conseguirá pôr em evidência suas crenças a respeito da realidade que está a sua volta. As respostas desencadeadas resultam de respostas de crianças quando são questionados sobre algo no qual nunca pensaram, porém, representam, não obstante, o seu pensamento e suas crenças. As respostas sugeridas, a fabulação e o não-importismo, quando dadas pela criança, devem ser descartadas no momento da análise dos resultados porque nesses casos as respostas podem ter sido induzidas; podem representar a imaginação da criança ou mesmo terem sido inventadas no momento da entrevista. Dessa forma, na apresentação dos resultados, as respostas que se encaixavam nessas situações foram descartadas.

\section{As crianças e os dilemas de sala de aula}

Os temas e subtemas decorrentes dos dilemas citados assim foram apresentados: temas: cooperação; agressão física e verbal; constituição e cumprimento de regras. Subtemas: conceito (crenças); empréstimo combinados; regras de jogos; noções de certo ou errado; sanções (castigos); justiça retributiva; justiça distributiva; quebra do elo de solidariedade; sanção expiatória; sanção por reciprocidade; crenças desencadeadas; moral heterônoma; a professora é quem determina; tem que obedecer; nova regra; deve punir; merece uma chance. 
A indisciplina na instituição escolar: o trabalho com assembleias de classe no desenvolvimento de crianças morais autônomas

Analisou-se o pensamento moral expresso no momento das assembleias de sala de aula, iniciando pelo agrupamento intitulado "dilemas da cooperação", o qual abarca dois subtemas, sendo o primeiro, empréstimo de materiais aos colegas (pode ou não emprestar?); e o segundo, a construção coletiva de regras. Esses fatos decorrentes da rotina de sala de aula tornaram-se dilemas a partir do momento em que foram problematizados e o espaço foi aberto para que os alunos pudessem pensar em como se estabeleceriam os acordos. Emprestar ou não materiais entre os alunos e como essa dinâmica transcorreria permitiu a exposição de opiniões diversificadas, despertando a necessidade de que uma regra se efetivasse no grupo-classe. Como necessidade do grupo, a regra é tomada como responsabilidade de todos, sentemse assim responsáveis por aquilo que os pertence (TOGNETTA; VINHA, 2008). Complementando, Macedo (1996), coloca que o caráter compreensivo (a regulação, aquilo que deve ser repetido em todas as circunstâncias) e extensivo das regras (o que deve ser respeitado por todos aqueles submetidos a ela) precisam ser considerados [e respeitados] pelo professor e seu grupo de alunos quando da construção das regras que organizarão os trabalhos, garantindo, assim, a justiça na classe. Cabe ressaltar que os sujeitos de nossa pesquisa encontram-se na fase de cooperação nascente (7-8 anos) que, de acordo com Piaget (1998, p. 120), "as regras começam a ser unificadas e o controle mútuo passa a substituir a obediência aos grandes".

No tema relacionado à agressão física e verbal, agregam-se os dilemas: regra do jogo de figurinhas: conflito devido ao não cumprimento da regra e meu amigo xingou minha mãe, e agora? Essas situações de conflito, comuns nas escolas, geralmente são tratadas pelos adultos com a punição dos envolvidos, com a intenção de diluir, o mais rápido possível, o transtorno causado no espaço escolar. Falas como: "a regra é clara, quem bateu e virou, fica com as figurinhas... caso contrário apanha"; "se você xingar minha mãe, recebe o troco". As manifestações dos alunos durante as assembleias deixaram evidentes, num primeiro momento, a noção de justiça retributiva, ou seja, que contempla a sanção, que deve seguir inevitavelmente todo delito (o que observamos em crianças de até 8 anos aproximadamente). Atreladas às noções de justiça, temos as sanções expiatórias (ligadas à coação, regras de autoridade, punição e recondução à obediência) quando a qualidade do castigo não condiz com a do delito, presentes nas crianças até por volta dos 7 anos. Por outro lado, o conceito de justiça distributiva ou igualitária implica o sentimento de igualdade, ao contrário da justiça retributiva. Nesse caso, surgem as sanções por reciprocidade (ligadas à cooperação e às regras de igualdade), como por exemplo, excluir alguém de um grupo porque mentiu e esta é incompatível com a confiança mútua, presentes nas crianças geralmente a partir dos 8-9 anos em média (LA TAILLE, 1992). O que se buscou nessas assembleias foi mediar uma discussão em que o ato cometido por ambos mereceu reprovação do grupo. Cabe observar que, na busca de alternativas para os dilemas deve se levar em consideração possíveis diferenças de crenças, valores e aspirações dos participantes, o que possibilita o avanço da moralidade e da justiça igualitária.

O tema constituição e cumprimento de regras abrange os dilemas: o que fazer quando o aluno não cumpre as regras da sala de aula?; ida ao banheiro: pedir 
ou não permissão à professora? e o não cumprimento de uma regra que passou despercebida - deve ou não haver punição? Se observarmos as concepções que estão implícitas nesse tema, promoveremos a reflexão acerca do que se propõe, enquanto contrato e prática pedagógica, que indicaria um equilíbrio entre a "situação simétrica e assimétrica" (PUIG, 2000) que ocorre na escola.

Analisaremos primeiramente a concepção da constituição de regras pelo grupo que supõe estabelecer, a priori, um ambiente participativo, constituído por valores procedimentais e atitudinais, como o diálogo e a autorregulação. A concretização desses valores refere-se à prática de representatividade do aluno nas decisões do grupo-classe e posteriormente na escola como um todo. Dessa mesma concepção, derivam-se algumas implicações como o favorecimento de um momento em que a palavra é exercida como meio de ação cooperativa e de tomada de consciência; um espaço que se define pela participação e interação entre os membros do grupo. O que se refere ao não cumprimento das regras da sala é algo bastante natural quando se relaciona com a consciência e internalização de um combinado. A não aceitação deste, por P., por exemplo, implica um reflexo da fase de heteronomia em que se encontra. A atitude apresentada por P. demonstra uma espécie de transgressão à regra social, feita em acordo mútuo pelo grupo. Essa conduta nos leva a duas reflexões: a primeira, a dificuldade de P. em relacionar-se com as propostas do grupo, pois suas atitudes egocêntricas não coincidem com as sugeridas na assembleia - por exemplo: fazer mais lições, copiar devagar etc., como sanção expiatória proposta pelo grupo. A segunda, a hipótese de reverter sua característica egocêntrica por meio de envolvimento em práticas cooperativas, ao exercício de autorregulação e descentração, sendo favorável à proposta de constituição de um ambiente cooperativo, envolvendo a sanção por reciprocidade - por exemplo: ajudar uma menina com dificuldade em copiar a lição.

Com relação ao dilema ida ao banheiro: pedir ou não permissão à professora, foi oferecida a possibilidade ao aluno de controlar autonomamente suas saídas de sala de aula (ir ao banheiro, beber água, etc.). Exemplo: M. quer ir ao banheiro - ele pode sair sem pedir permissão à professora? Essa situação problematizada pela professora evidenciou pensamentos morais importantes, como a admiração do grupo perante a possibilidade de autogovernar-se; o sentimento de respeito ou desrespeito na posição de "igualdade" de decisão com a professora e o medo de superação da responsabilidade heterônoma. O acordo decorrente da assembleia expôs o seguinte combinado: havendo a necessidade, o aluno poderia sair sem pedir à professora, desde que observasse o sinal verde ou vermelho nos cartões, significando que um aluno já estaria no banheiro. Portanto, essas situações propostas dão a possibilidade de promover o exercício da autorregulação, o qual se vincula à prática do self-government, dados como oportunidade no desenvolvimento das assembleias (PIAGET, 1998).

Finalizando, "o conflito emergido: o não cumprimento de uma regra que passou despercebida - deve ou não haver punição?” é decorrente do dilema anterior, quando J.A., sem perceber, infringiu um combinado pelo grupo, ou seja, ele saiu da sala sem observar os cartões que indicariam a possibilidade de sair ou 
A indisciplina na instituição escolar: o trabalho com assembleias de classe no desenvolvimento de crianças morais autônomas

não da sala. Esse fato desencadeou manifestação dos alunos que colocaram esta situação na pauta da assembleia seguinte. A prática de discussão através do diálogo implica adquirir a capacidade de autorregulação e autoconhecimento, capacidade esta que será alcançada por meio da inserção do indivíduo em situações em que o desequilíbrio moral o faça estabelecer relações com o conhecimento anterior que possui, e assim construir, gradativamente, a sua autonomia moral (COLOMBO; DIAS, 2010) e intelectual garantindo assim a participação do indivíduo nos espaços de tomada de decisão, com as possíveis diferenças de crenças, valores e aspirações, democratizando assim a convivência coletiva e as relações interpessoais (ARAÚJO, 2002).

\section{Considerações finais}

Com a perspectiva de superação de problemas de indisciplina, através de um ambiente cooperativo, a utilização de recursos como as assembleias de sala de aula fica evidenciada no presente estudo. O espaço das assembléias de classe permite experiências conceituais concretas e práticas de democracia na escola, que poderão levar todos os membros da comunidade a vivenciarem um ambiente democrático e respeitoso, contribuindo para a educação moral e para a cidadania.

Cabe ressaltar que o trabalho em sala de aula não transcorre baseado apenas na cognição, pois há uma grande carga afetiva envolvida, podendo passar por agressão, busca de afeto ou aceitação, e por fim, enfrentar situações de conflito. Há que se fazer todo um trabalho educativo, preventivo, tendo como possibilidade a prática de assembleias.

Portanto, a ação educativa exercida, que vai além da transmissão de conteúdos curriculares, deve promover também a formação moral de seus alunos.

O exercício com as assembleias se configura como um espaço oportuno em que o professor pode conhecer melhor seus alunos e estes se conhecerem mutuamente. As regras são elaboradas e reelaboradas em conjunto em que se discutem os conflitos e se propõem soluções; em que se vivencia a democracia, pautada no respeito mútuo como princípio básico das relações interpessoais e direcionamento das ações.

É importante lembrar que as assembleias, mesmo como possibilidade de um trabalho educativo e preventivo, não são mágica ou panaceia que solucionam e eliminam todos os problemas, contudo elas se traduzem "como possibilidade de evolução moral dos sujeitos que delam participam [...]”. (TOGNETTA; VINHA, 2008, p. 60).

A expectativa deste estudo é a de que se ofereçam elementos de base e orientação aos educadores, para que busquem estreitar a compreensão na prática das relações que emergem do contexto escolar e ainda, evidenciar que, apesar da faixa etária dos nossos sujeitos de pesquisa ( $7-8$ anos), houve um percurso por meio de assembleias, que demonstrou a possibilidade de construção da autonomia moral. 


\section{Referências}

AQUINO, J. G. Do cotidiano escolar: ensaios sobre a ética e seus avessos. São Paulo: Summus, 2000.

A desordem na relação professor-aluno: indisciplina, moralidade e conhecimento. In: __ (Org.). Indisciplina na escola: alternativas teóricas e práticas. São Paulo: Summus, 1996, p. 39-55.

ARAÚJO, U. F. A construção de escolas democráticas: histórias sobre complexidade, mudanças e resistências. São Paulo: Moderna, 2002.

ARGÜÍS, R. et al. Tutoria: com a palavra, o aluno. Trad. Fátima Murad. Porto Alegre: Artmed, 2002.

COLOMBO,T. F. da S.; DIAS, G. L. Desenvolvimento sociomoral no contexto escolar: uma experiência com crianças do ciclo I - Ensino Fundamental. Rev. Psicopedagogia, v. 27, n. 82, 2010, p. 3-14.

DELVAL, J. Introdução à prática do método clínico: descobrindo o pensamento das crianças. Trad. Fátima Murad. Porto Alegre: Artmed, 2002.

LA TAILLE, I. Desenvolvimento do juízo moral e afetividade na teoria de Jean Piaget. In: LA TAILLE, I.; OLIVEIRA, M.K. de; DANTAS, H. Piaget, Vygotsky, Wallon: teorias psicogenéticas em discussão. São Paulo: Summus, 1992.

LA TAYLLE, Y; SILVA, N.P.; JUSTO, J. S. Indisciplina/disciplina: ética, moral e ação do professor. Porto Alegre: Mediação, 2006.

MACEDO, L. Cinco estudos de educação moral. São Paulo: Casa do Psicólogo, 1996.

MONTOYA, A. O. D. Contribuições da psicologia e epistemologia genéticas para a educação. In: CARRARA, K. (Org.). Introdução à psicologia da educação: seis abordagens. São Paulo: Avercamp, 2004, p. 157-186.

PAPPA, J. S. A (in)disciplina e a violência escolar segundo a concepção de professores do ensino fundamental. Marília, 2003. 171f. Tese (doutorado). Universidade Estadual Paulista Júlio de Mesquita Filho.

PARRAT-DAYAN, S. Como enfrentar a indisciplina na escola. São Paulo: Contexto, 2008.

PIAGET, J. O juízo moral na criança. São Paulo: Summus, 1994.

. Observações psicológicas sobre o self-government. In: PARRAT, S. \& TRYPHON, A. (Org.). Jean Piaget - sobre a pedagogia. Trad. Cláudia Berliner. São Paulo: Casa do Psicólogo, 1998, p. 113-129.

PUIG, J. M. Ética e valores: métodos para um ensino transversal. Trad. Ana V. Fuzatto. São Paulo: Casa do Psicólogo. 1988.

., et al. Democracia e participação escolar: propostas de atividades. Tradução Maria C. de Oliveira. São Paulo: Moderna, 2000.

REGO, T. C. R. A indisciplina e o processo educativo: uma análise na perspectiva vygotskiana. In: AQUINO, J.G. (Org.). Indisciplina na escola: alternativas teóricas e práticas. São Paulo: Summus, 1996, p.83-101.

TOGNETTA, L. R. P.; VINHA, T. P. Quando a escola é democrática: um olhar sobre a prática das regras e assembleias na escola. Campinas, São Paulo: Mercado das Letras, 2008.

VASCONCELLOS, C. dos S. Disciplina: construção da disciplina consciente e interativa em sala de aula e na escola. São Paulo: Libertad, 2000. 


\title{
A indisciplina na instituição escolar: o trabalho com assembleias de classe no desenvolvimento de crianças morais autônomas
}

\section{Notas}

\begin{abstract}
${ }^{1}$ O próprio conceito de indisciplina, como toda criação cultural, não é estático, uniforme, nem tampouco universal. Ele se relaciona com um conjunto de valores e expectativas que variam ao longo da história, entre as diferentes culturas e numa mesma sociedade (REGO, 1996, p. 84).

${ }^{2}$ Nível ou segmento - participam os professores e dois representantes de cada classe, o coordenador, o orientador e o representante dos funcionários. Escola - participam os representantes de todos os segmentos da comunidade escolar (rodízio) e com a coordenação de um integrante da direção. Docentes - participam todos os docentes, a direção da escola, representantes da secretaria de educação ou mantenedora (TOGNETTA; VINHA, 2008, p. 63).
\end{abstract}

* Carmen Lúcia Dias - Docente do Programa de Mestrado em Educação da Universidade do Oeste Paulista - Presidente Prudente, São Paulo, Brasil.

** Terezinha Ferreira da Silva Colombo - Docente e coordenadora do curso superior em Pedagogia do Instituto de Ensino Superior de Garça, São Paulo, Brasil.

\section{Correspondência}

Carmen Lúcia Dias - Universidade do Oeste Paulista, Mestrado em Educação.

Rodovia Raposo Tavares, Km 572 - Campus II, Limoeiro

CEP: 19067-175 - Presidente Prudente, São Paulo, Brasil.

E-mail:kkaludias@gmail.com - tfcolombo@terra.com.br

Recebido em 06 de dezembro de 2012

Aprovado em 06 de março de 2013 
